Table 1. Effect of the Efflux Pump Inhibitor on Ceftolozane/Tazobactam and Meropenem MIC Values Among Meropenem-Nonsusceptible MBL-producing and Non-MBL-producing Pseudomonas aeruginosa

\begin{tabular}{|c|c|c|c|c|c|}
\hline \multirow[b]{2}{*}{ No. of Isolates } & \multirow[b]{2}{*}{ Efflux Pump } & \multirow[b]{2}{*}{ MBL Gene } & \multirow{2}{*}{$\begin{array}{c}\mathrm{C} / \mathrm{T} \mathrm{MIC}^{\mathrm{a}} \\
\text { Range, } \mu \mathrm{G} / \mathrm{ML}\end{array}$} & \multicolumn{2}{|c|}{$\begin{array}{l}\text { Meropenem MICb } \\
\text { Range, } \mu \mathrm{g} / \mathrm{mL}\end{array}$} \\
\hline & & & & Without $\mathrm{Pa} \beta \mathrm{N}$ & With $\mathrm{Pa} \beta \mathrm{N}$ \\
\hline 2 & MexAB-XY & $b l a_{\mathrm{IMP}}$ & $>256.0$ & $256.0-128.0$ & $2.0-8.0$ \\
\hline 12 & MexAB-XY & $b l a_{\mathrm{SPM}-1}$ & $>256.0$ & 256.0 & $4.0-8.0$ \\
\hline 1 & MexAB & $b l a_{\mathrm{SPM}-1}$ & $>256.0$ & 256.0 & 16.0 \\
\hline 10 & MexXY & None & $0.75-4.0$ & 256.0 & $8.0-16.0$ \\
\hline 8 & MexXY & None & $1.0-2.0$ & $8.0-64.0$ & 1.0 \\
\hline 6 & MexXY & None & 1.0 & 16.0 & $0.5-1.0$ \\
\hline 16 & MexXY & None & $1.0-2.0$ & $8.0-32.0$ & $0.5-1.0$ \\
\hline 12 & MexAB & None & $0.75-2.0$ & $16.0-32.0$ & 1.0 \\
\hline 10 & MexAB & None & 1.0 & 16.0 & $1.0-2.0$ \\
\hline 14 & MexAB & None & $1.0-4.0$ & $8.0-32.0$ & $1.0-2.0$ \\
\hline
\end{tabular}

Note. MBL, metallo- $\beta$-lactamase; MIC, minimum inhibitory concentration; Pa $\beta \mathrm{N}, \mathrm{L}$-phenyl-L-arginine $\beta$-naphthylamide. ${ }^{\mathrm{a}} \mathrm{C} / \mathrm{T}$ (ceftolozane/tazobactam) break points are $\leq 4 \mu \mathrm{g} / \mathrm{mL}$ (susceptible) and $>4 \mu \mathrm{g} / \mathrm{mL}$ (resistant).

${ }^{b}$ Meropenem break points are $\leq 4 \mu \mathrm{g} / \mathrm{mL}$ (susceptible) and $\geq 16 \mu \mathrm{g} / \mathrm{mL}$ (resistant).

Financial support. No financial support was provided relevant to this article.

Conflicts of interest. The author report no conflicts of interest relevant to this article.

\section{References}

1. Bush K, Jacoby GA. Updated functional classification of beta-lactamases. Antimicrob Agents Chemother 2010;54:969-976.

2. Perez LR, Antunes AL, Freitas AL, Barth AL. When the resistance gets clingy: Pseudomonas aeruginosa harboring metallo-beta-lactamase gene shows high ability to produce biofilm. Eur J Clin Microbiol Infect Dis 2012;31:711-714.

3. Cabot G, Ocampo-Sosa AA, Tubau F, Macia MD, Rodriguez C, Moya B, Zamorano L, Suarez C, Pena C, Martinez-Martinez L, Oliver A. Spanish network for research in infectious diseases (REIPI). Overexpression of AmpC and efflux pumps in pseudomonas aeruginosa isolates from bloodstream infections: prevalence and impact on resistance in a Spanish multicenter study. Antimicrob Agents Chemother 2011;55:1906-1911.

4. Livermore DM, Mushtaq S, Meunier D, Hopkins KL, Hill R, Adkin R, Chaudhry A, Pike R, Staves P, Woodford N, the BSAC Resistance
Surveillance Standing Committee. Activity of ceftolozane/tazobactam against surveillance and 'problem' enterobacteriaceae, pseudomonas aeruginosa and non-fermenters from the British Isles. J Antimicrob Chemother 2017;72:2278-2289.

5. Cattoir V. Efflux-mediated antibiotics resistance in bacteria. Pathol Biol 2004;52:607-616.

6. Poole K. Pseudomonas aeruginosa: resistance to the max. Front Microbiol 2011;2:65.

7. Lamers RP, Cavallari JF, Burrows LL. The efflux inhibitor phenylalaninearginine beta-naphthylamide $(\mathrm{PA} \beta \mathrm{N})$ permeabilizes the outer membrane of gram-negative bacteria. Plos One 2013;8:e60666.

8. Clinical and Laboratory Standards Institute (CLSI). Performance Standards for Antimicrobial Susceptibility Testing. Wayne, PA: CLSI; 2018.

9. Mesaros N, Glupczynski Y, Avrain L, Caceres NE, Tulkens PM, Van Bambeke F. A combined phenotypic and genotypic method for the detection of Mex efflux pumps in Pseudomonas aeruginosa. J Antimicrob Chemother 2007;59:378-386.

10. Lomovskaya O, Bostian KA. Practical applications and feasibility of efflux pump inhibitors in the clinic—a vision for applied use. Biochem Pharmacol 2006;71:910-918.

\title{
Forecasting from phenotypic testing to an antimicrobial stewardship strategy: Does the time to positivity of a blue-carba test predict the meropenem susceptibility level among carbapenemase producers?
}

\author{
Leandro Reus Rodrigues Perez PhD (1) \\ Hospital Mãe de Deus, Porto Alegre, Brazil
}

Author for correspondence: Leandro Reus Rodrigues Perez, PhD, Microbiology Unit, Hospital Mãe de Deus, 286, José de Alencar Street, 90610-000, Porto Alegre - RS, Brazil. Email: leandro.reus@gmail.com

Cite this article: Perez LRR. (2019). Forecasting from phenotypic testing to an antimicrobial stewardship strategy: Does the time to positivity of a blue-carba test predict the meropenem susceptibility level among carbapenemase producers? Infection Control \& Hospital Epidemiology, 40: 958-960, https://doi.org/10.1017/ice.2019.158
To the Editor-Currently, carbapenem-resistant Enterobacterales (CRE) have emerged worldwide at an alarming rate, causing both community and nosocomial infections. ${ }^{1}$ Carbapenem-resistance may be related to a decrease in bacterial outer-membrane 


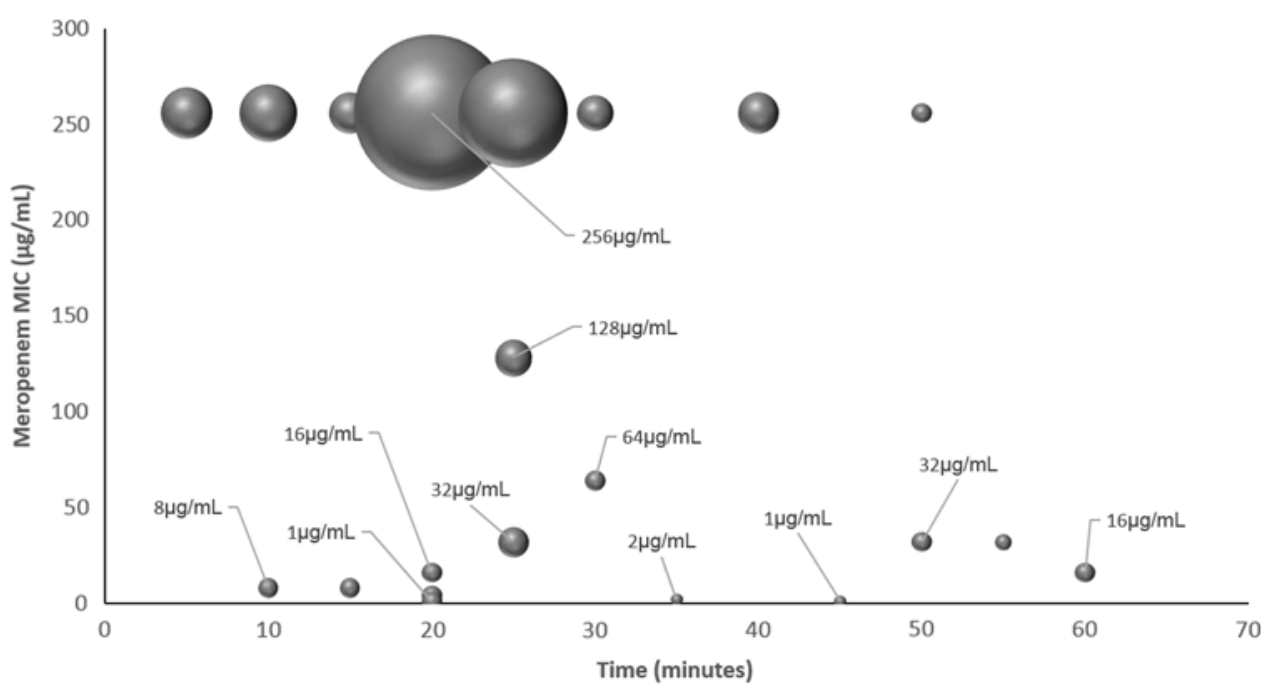

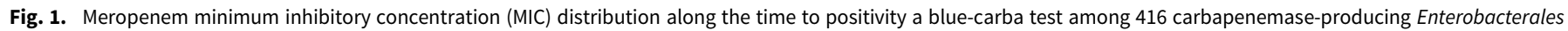
isolates. The size of the circles are representative of the number of isolates with the same time-MIC profile.

permeability associated with an overexpression of $\beta$-lactamases with no carbapenemase activity, such as extended spectrum $\beta$-lactamases (ESBLs) and/or ampC enzymes, or due to a carbapenemase itself. ${ }^{2}$

To rapidly identify carbapenemase producers among Enterobacterales, phenotypic tests, such as Carba NP and the blue-carba test, based on in vitro imipenem hydrolysis, were developed. They have demonstrated very good correlation with the presence of Klebsiella pneumoniae carbapenemase (KPC) or metallo- $\beta$-lactamases (MBLs), with less accuracy for the OXA family., The latter group is generally a group of enzymes with a lower carbapenem hydrolysis capacity than the other carbapenemases, and they often require a longer time for a positive phenotypic test. ${ }^{3}$ Predicting the susceptibility level, currently, is crucial for decision making regarding antimicrobial therapy and, consequently, a better clinical outcome. For this reason, we sought to resolve an interesting question: Does the time required to obtain a positive phenotypic test have any relation to the carbapenem resistance level observed? We investigated the time to positivity required when the blue-carba phenotypic test was applied, and we compared the results to the meropenem minimum inhibitory concentration (MIC) for each isolate evaluated.

Carbapenemase-producing Enterobacterales (CPE) isolates, which were obtained during a 1-year follow-up epidemiologic study from January 2016 to February 2017 in Southern Brazil, were identified by conventional biochemical tests and by matrix-assisted laser desorption/ionization time-of-flight mass spectroscopy (MALDI-TOF MS) when necessary. All isolates also contained the carbapenemase gene detected by polymerase chain reaction (PCR) performed as previously described. ${ }^{5}$ Meropenem MICs were determined using the broth microdilution method performed in house. The results were recorded according to US guidelines (ie, the Clinical and Laboratory Standards Institute). ${ }^{6}$ The bluecarba test was performed in triplicate, as previously described, ${ }^{4}$ and the results were read after each 5-minute period, from the beginning of incubation until enough time for a definitive color change. Escherichia coli ATCC 25922 (negative control) and K. pneumoniae ATCC BAA-1706 (positive control; time to positivity a blue-carba test ranging from 15 to 20 minutes) were used for quality control.

During the study period, a total of $416 \mathrm{CPE}$ isolates were evaluated, and 413 (99.3\%) were KPC producer:s 396 Klebsiella pneumoniae, 10 Escherichia coli, 4 Serratia marcescens, 1 K. oxyoca, 1 Citrobacter freundii and 1 Enterobacter cloacae complex. The remaining 3 isolates $(0.7 \%)$ were New Delhi metallo- $\beta$-lactamase (NDM) producers; all of these were $K$. pneumoniae isolates.

When the blue-carba test was applied, the color of the wells turned from blue to green or yellow for all tested strains, indicating their meropenem susceptibility level. For 266 (63.9\%) isolates, the color change began as early as 20 minutes after incubation for KPC and NDM producers. In most cases (390 isolates, 93.8\%) incubation for 30 minutes was enough to obtain a definitive color change (Figure 1). Notably, most of our isolates $(\mathrm{n}=371,89.2 \%)$, including the $3 \mathrm{NDM}$-producing ones, presented a meropenem MIC $\geq 256 \mu \mathrm{g} / \mathrm{mL}$. Among them, only 16 isolates $(16$ of $371 ; 4.3 \%)$ gave a positive result after 30 minutes of incubation (Figure 1). In contrast, 25 isolates (6.0\%) with lower meropenem MICs $(\leq 64 \mu \mathrm{g} / \mathrm{mL})$ gave a positive result, even with $<30$ minutes of incubation. Thus, the enzymatic speed for hydrolysis, inferred by the time required to gain a positive blue-carba test, does not necessarily reflect the resistance level promoted by this enzyme.

Some experiments indicated that $b l a_{\mathrm{KPC}}$ and $b l a_{\mathrm{NDM}}$ readily hydrolyzed carbapenems. ${ }^{7}$ For some substrates, however, rapid kinetic activity is observed (enough for a blue-carba positive but not exact enough to determine an MIC value), followed by a slower phase before the completion of hydrolysis (which may be complementary to turn positive a blue-carba test but is mandatory to establish a true MIC value).

Gene expression, amount of enzyme produced, and hydrolysis potency may exert some influence on the time to positivity in a phenotypic test. OXA enzymes, for example, possess low hydrolytic-carbapenem activity and probably lower MICs as well. ${ }^{4}$ Additionally, KPC and NDM may present high resistance levels (high MICs) with varied hydrolysis rates with different times to positivity than the blue-carba test.

Our study has several potential limitations. No molecular background information about isolates was available. A high number of KPC producers may represent an overestimation of a single clone or enzyme. Also, we compared the blue-carba test (using $3 \mu \mathrm{g} / \mathrm{mL}$ imipenem) with the meropenem MIC.

The results obtained from a positive blue-carba test are crucial for an infection control strategy and therapeutic approaches. However, 
the time to positivity does not necessarily correlate with either the type of enzyme involved or the level of resistance produced by it. However, high meropenem MICs have been observed more frequently among isolates that presented a blue-carba test positive in $<30$ minutes (Figure 1).

In conclusion, this is the first report evaluating the time required to obtain a positive blue-carba test. It is particularly useful in a setting with endemic prevalence of KPC enzyme, which occurs in many countries, including Brazil. ${ }^{5}$ The results presented here demonstrate that this test is not valuable for the prediction of meropenem susceptibility. Further studies involving other carbapenemase types should be conducted for a more accurate evaluation.

Author ORCIDs. Leandro Reus Rodrigues Perez (D) 0000-0002-6662-6503

Acknowledgments. The author would like to thank Sophia Perez for the technical support.

Financial support. This study was funded in part by $\mathrm{CNPq}$, Brazil.

Conflicts of interest. The author report no conflicts of interest relevant to this article.

\section{References}

1. Castanheira M, Deshpande LM, Mendes RE, Canton R, Sader HS, Jones RN. Variations in the occurrence of resistance phenotypes and carbapenemase genes among Enterobacteriaceae isolates in 20 years of the SENTRY Antimicrobial Surveillance Program. Open Forum Infect Dis 2019;6:S23-S33.

2. Drew RJ, Turton JF, Hill RLR, et al. Emergence of carbapenem-resistant Enterobacteriaceae in a UK paediatric hospital. J Hosp Infect 2013;84: 300-304.

3. Poirel L, Nordmann P. Rapidec Carba NP Test for rapid detection of carbapenemase producers. J Clin Microbiol 2015;53:3003-3008.

4. Pires J, Novais A, Peixe L. Blue-carba, an easy biochemical test for detection of diverse carbapenemase producers directly from bacterial cultures. J Clin Microbiol 2013;51:4281-4283.

5. Rodrigues Perez LR. Carbapenem-resistant Enterobacteriaceae: a major prevalence difference due to the high performance of carbapenemase producers when compared to the nonproducers. Infect Control Hosp Epidemiol 2015;36:1480-1482.

6. Clinical and Laboratory Standards Institute (CLSI). Performance Standards for Antimicrobial Susceptibility Testing. Wayne, PA: CLSI; 2018.

7. Santucci M, Spyrakis F, Cross S, et al. Computational and biological profile of boronic acids for the detection of bacterial serine- and metallo- $\beta$-lactamases. Sci Rep 2017;7:17716. 